\title{
EMISAR single pass topographic SAR interferometer modes
}

\author{
Madsen, Søren Nørvang; Skou, Niels; Woelders, Kim; Granholm, Johan
}

Published in:

Proceedings of the International Geoscience and Remote Sensing Symposium

Link to article, DOI:

10.1109/IGARSS.1996.516439

Publication date:

1996

Document Version

Publisher's PDF, also known as Version of record

Link back to DTU Orbit

Citation (APA):

Madsen, S. N., Skou, N., Woelders, K., \& Granholm, J. (1996). EMISAR single pass topographic SAR interferometer modes. In Proceedings of the International Geoscience and Remote Sensing Symposium: Remote Sensing for a Sustainable Future (Vol. Volume 1, pp. 674-676). IEEE. https://doi.org/10.1109/IGARSS.1996.516439

\section{General rights}

Copyright and moral rights for the publications made accessible in the public portal are retained by the authors and/or other copyright owners and it is a condition of accessing publications that users recognise and abide by the legal requirements associated with these rights.

- Users may download and print one copy of any publication from the public portal for the purpose of private study or research.

- You may not further distribute the material or use it for any profit-making activity or commercial gain

- You may freely distribute the URL identifying the publication in the public portal 


\title{
EMISAR Single pass Topographic SAR interferometer modes
}

\author{
S. N. Madsen, N. Skou, K. Woelders, and J. Granholm \\ Danish Center for Remote Sensing, Dept. of Electromagnetic Systems \\ Technical University of Denmark, B-348, DK-2800 Lyngby, Denmark \\ Phone: +45 4525 3800, Fax: +45 4593 1634, E-mail: snm@emi.dtu.dk
}

\begin{abstract}
The Danish Center for Remote Sensing (DCRS ${ }^{1}$ ) has augmented its dual-frequency polarimetric synthetic aperture radar system (EMISAR ${ }^{2}$ ) with single pass acrosstrack interferometric (XTI) modes. This paper will describe the system configuration, specifications and the operating modes. Analysis of data acquired in 1995 indicates that height resolutions better than one meter should be attainable at least in areas with benign topography where overlay, shadows and phase unwrapping errors are minimal. Calibration procedures applied to correct for multipath and limited channel isolation are discussed.
\end{abstract}

\section{INTRODUCTION}

A single pass across-track interferometer uses two antennas displaced across-track to acquire two images observing all image points from two slightly different angles of incidence. By overlaying the two complex SAR images during processing and determining the phase differences (interference generation), slant range differences can be determined with fractional wavelength accuracy. From slant range, differential slant range measurements, and knowledge of the baseline (= displacement from one antenna to the other) the 3-D target location can be determined. A single pass system acquires the two complex images forming the interferogram simultaneously thus there is no temporal decorrelation due to target displacement. As the antennas forming the baseline are rigidly connected, and the orientation can be measured by an inertial navigation system, the baseline is well defined and generally known to great accuracy which is seldom the case in repeat pass systems. The single pass concept does, however, limit the baseline to a length which can practically be implemented on the aircraft platform available.

Defining the interferogram as the product of channel 1 and the complex conjugate of channel 2 , the interferometric phase is,

$$
\phi=\phi_{1}-\phi_{2}=p \frac{2 \pi}{\lambda}\left(\rho_{2}-\rho_{1}\right)
$$

1 The Danish Center for Remote Sensing is finansed by the Danish National Research Foundation.

2 Development of EMISAR has been supported by the Thomas B. Thriges Foundation, the Danish Technical Research Counsil (STVF), the Royal Danish Air Force (RDAF), the Technical University of Denmark, the Joint Research Centre (JRC) and by the Danish National Research Foundation. $p=1$ if the transmit antenna is common for the two channels, $p=2$ if each channel uses only one antenna to both transmit and receive. $\lambda$ is wavelength and $\rho_{i}$ is slant range. The phase measured in the interferogram, $\phi_{M}$, is the absolute phase of (1) modulus $2 \pi$. Getting from $\phi_{M}$ to $\phi$, involves two steps called phase-unwrapping and absolute phase determination, see for instance [1] and [2]. Assuming the geometry of Fig. 1, the look angle $\theta$ and the interferometric phase are related by (assuming $B \ll<$ ):

$$
\sin (\theta-\alpha)=\cos \left(\theta-\theta_{21}\right) \approx \frac{\rho_{1}-\rho_{2}}{B}=\frac{-\lambda \phi}{2 \pi p B}
$$

$\alpha$ is the baseline orientation relative to horizontal. It is trivial to solve for the target height and across-track position:

$$
\begin{aligned}
& \theta=\alpha-\arcsin \left(\frac{\lambda \phi}{2 \pi p B}\right) \\
& h=H-\rho_{1} \cos \theta \\
& y=\rho_{1} \sin \theta
\end{aligned}
$$

A more general geometry allowing for non zero Doppler geometry is discussed in [3] and analyses of accuracies and error sources are presented in [4] and [5]. As it is intuitively clear, the signal-to-noise ratio will limit performance as thermal noise induces phase errors which via (3) couple to the look angle leading to wrong height and cross track positions. Similarly, baseline orientation errors (here presented by $\alpha$ ) will cause position errors although these errors will be slowly varying over the image.

A less intuitive error source is baseline decorrelation which occurs because not all targets within the resolution cell contribute the same interferometric phase. For the very short baselines applied in the system discussed here, baseline

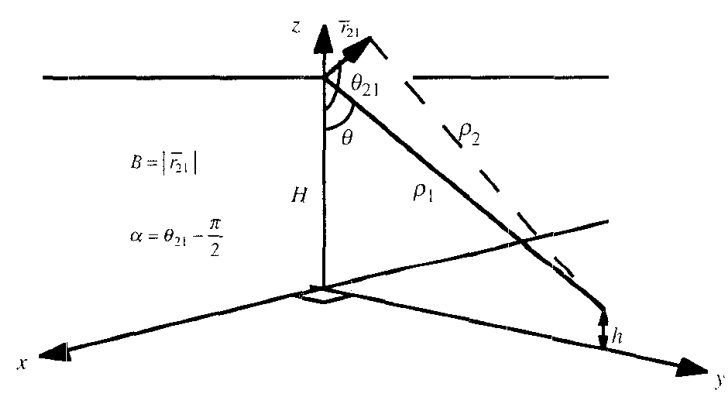

Fig. 1. Across-track interferometric geometry. 
Table 1. EMISAR system parameters for polarimetric and interferometric modes.

\begin{tabular}{|l|cc|}
\hline \hline Parameter & C-band & L-band \\
\hline Polarimetry: & $5.67 \mathrm{~cm}$ & $24.0 \mathrm{~cm}$ \\
wavelength & $2 \mathrm{~kW}$ & $6 \mathrm{~kW}$ \\
transmit power & $27 \mathrm{~dB}$ & $18 \mathrm{~dB}$ \\
antenna gain & \multicolumn{2}{|c|}{$100 \mathrm{MHz}$} \\
max. bandwidth & $8192 \mathrm{~V} / \mathrm{Q}$ samples \\
digitization & $\mathrm{I}+\mathrm{Q}=8+8 \mathrm{bits}$ \\
& quad-pol, hh/vv/hv/vh \\
polarization & left \\
look direction & \multicolumn{2}{|c|}{$41,000 \mathrm{ft}}$. \\
nominal altitude & \multicolumn{2}{|c|}{} \\
Interferometry: & $5.67 \mathrm{~cm}$ \\
wavelength & dual-pol: HH/VV \\
polarization & $1137 \mathrm{~mm}$ \\
baseline length & $34.0^{\circ}$ \\
baseline angle, $\alpha$ & 25,000 or $41,000 \mathrm{ft}$. \\
nominal altitude & \\
\hline \hline
\end{tabular}

decorrelation is a minor importance.

\section{SAR SYSTEM}

The radar used, EMISAR, is an $\mathrm{L}$ - and $\mathrm{C}$-band polarimetric SAR developed at the Electromagnetics Institute since 1986. The system is flown on a Danish Air Force Gulfstream G-3. The transmitted bandwidth is up to $100 \mathrm{MHz}$, and the system is usually operated at $41^{*}: 000 \mathrm{ft}$ altitude. Some system parameters are listed in Table 1. Two flush mounted C-band antennas have been added to the system to support the single pass interferometric mode, Fig. 2.

The system presently use a combination of an inertial navigation system and a P-code GPS system to provide the required navigational information.

The XTI antennas are (like the existing pod antenna) fully polarimetric, and they are connected to a switch matrix mounted in the pod. Both antennas can be operated in a polarimetric mode, and interferometric data can be collected on both like polarizations, $\mathrm{HH}$ and/or VV. The radar front-

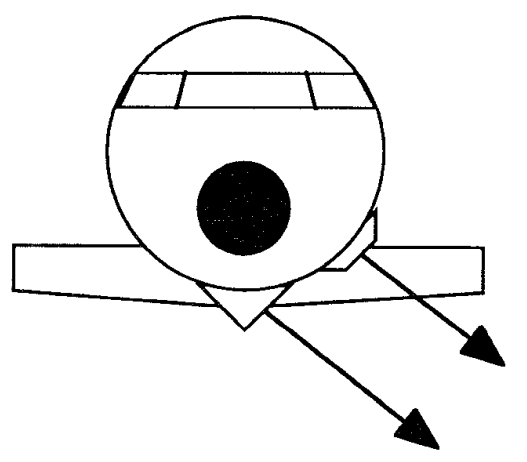

Fig. 2. Single pass interferometry use two polarimetric antennas flush mounted on G-3 fuselage in front of wing. end and data rate limitations does not presently support polarimetric interferometric data to be collected at high resolution. Several interferometric modes of operation are possible, including: 1) single baseline (transmit on one antenna, receive on both); 2) double baseline (sequentially transmit and receive on one antenna then transmit and receive on the other); and 3) dual baseline (sequentially transmit on one antenna and receive on both, then transmit on the other and receive on both).

\section{MULTIPATH CORRECTION}

The initial test of the EMISAR single pass mode showed that the limiting performance factor was multipath on the radar platform. It is import to note that the interferometric derivations (1-5) assumes a single signal path with the signal propagating from the transmit antenna, to the target, and back to the receive antenna. In any practical system there will, however, be reflections of parts of the aircraft platform which will also be received, and limited isolation between the two interferometric antennas also leads to multi-path. A leakage to/from the other antenna can be seen to be equivalent to a multipath reflection of the other antenna.

If the ideal signal for channel $i$ is $c_{i}=a_{i} \exp \left\{j \phi_{i}\right\}$ then the injection of a leakage signal from channel 2 to channel 1 will modify the interferometric phase as

$$
\begin{aligned}
\left(c_{1}+\varepsilon c_{2}\right) c_{2}{ }^{*} & =\left(a_{1} \exp \left\{j \phi_{1}\right\}+\varepsilon a_{2} \exp \left\{j \phi_{2}\right\}\right) a_{2} \exp \left\{-j \phi_{2}\right\} \\
& =a_{1} a_{2} \exp \{j \phi\}\left(1+\varepsilon \frac{a_{2}}{a_{1}} \exp \{j \phi\}\right)
\end{aligned}
$$

and even for more complex situations it is easily seem that the measured phase is a function of the ideal phase,

$$
\phi_{m}=\phi+\Delta \phi(\phi)
$$

As a full discussion of parameter calibration in an interferometric system is very complex we assume in the following that parameters such as baseline (length and orientation), aircraft orientation, channels delays and phases are already calibrated. Differentiating (4) with respect to the absolute phase provides

$$
\begin{aligned}
\partial h & =\rho \sin \left(\alpha-\arcsin \left(\frac{\lambda \phi}{2 \pi p B}\right)\right) \frac{-1}{\sqrt{1-\left(\frac{\lambda \phi}{2 \pi p B}\right)^{2}}} \frac{\lambda}{2 \pi p B} \partial \phi \\
& =\frac{-y}{\sqrt{1-\left(\frac{\lambda \phi}{2 \pi p B}\right)^{2}}} \frac{\lambda}{2 \pi p B} \partial \phi
\end{aligned}
$$

This shows that for small errors in the absolute phase (a requirement meet for any reasonable system), the error can be determined if the height error is known as a function of the across-track ground range and the absolute phase. The EMISAR system has been calibrated on several occasions by mapping ocean that provides a well defined height reference. It has been found that there seem to be two dominating multipath sources, one is a channel cross coupling at an 


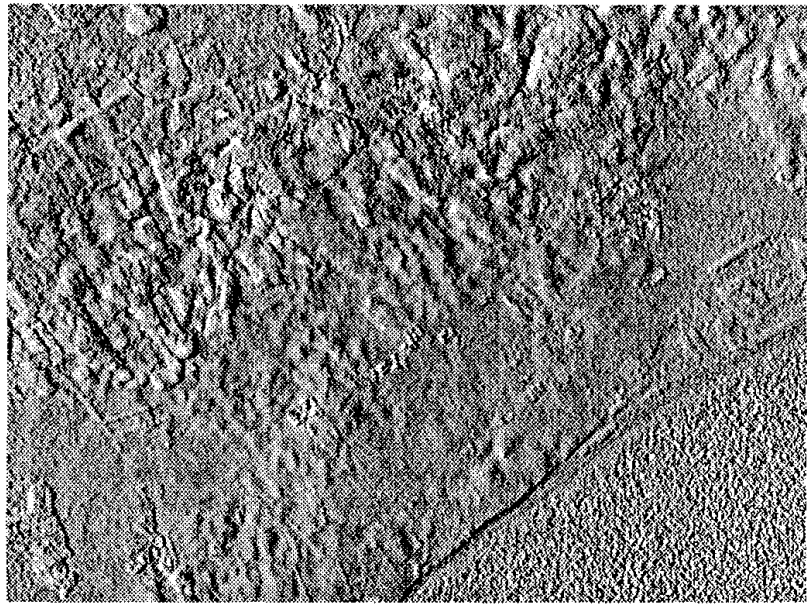

Fig. 3. Shaded relief map of a $5.2 \times 3.8 \mathrm{~km}$ subsection of a radar generated height map. Data were acquired from an altitude of $25,000 \mathrm{ft}$. Note the clear signature of the buildings near the center of the image. The area in the lower right hand corner is water.

approximately $-40 \mathrm{~dB}$ level, the other is an unknown reflection of the fuselage or antenna fairings with an equivalent baseline of approximately $20 \mathrm{~cm}$. The calibration phase screen has been found to be basically identical from mission to mission.

\section{PROCESSING}

The EMISAR azimuth presummers are presently not able to process Doppler off-sets varying with range, thus interferometric acquisitions are data rate limited to 6144 complex range samples. In the high resolution mode this gives a slant range swath of $6500 \mathrm{~m}$ after range pulse compression. Depending on the actual data acquisition geometry this translates into between 8 and $10 \mathrm{~km}$ ground range swath. The processing scheme applied is based on processing techniques developed at JPL, [3], [6]. The processor simultaneously processes the two interferometric channels which are then motion compensated to a common reference line, [7]. The processor also includes automatic determination of the absolute phase, [2]. The output products include co-registered amplitude data, height map, correlation map, and for calibration runs also absolute phase maps. The output data sets are orthorectified to a spherical $(s, c, h)$ coordinate system, [8]. Usually output products are generated at 5 or $10 \mathrm{~m}$ ground range pixel spacing.

\section{RESULTS}

Significant amounts of data were acquired during 1995 in both Denmark and Greenland indicating height accuracies before multipath calibration on the order of 5 to 10 meter. By applying the above described phase screen calibration technique, systematic errors have been drastically reduced. Analyses of data acquired in Denmark where the topographic relief is moderate (heights vary from 0 to $137 \mathrm{~m}$ in the data analyzed) indicates that the height error after removing a tilted plane is from $1 \mathrm{~m}$ in the near range to $3 \mathrm{~m}$ in the far range (at $10 \mathrm{~m}$ horizontal pixel spacing) when operating from $41,000 \mathrm{ft}$. Data acquired in the double baseline mode on a $25,000 \mathrm{ft}$. pass over the same area indicates stochastic height errors of $0.6 \mathrm{~m} \mathrm{rms}$. in the far range. Studies are presently ongoing to evaluate the height error performance in more detail, however, sufficiently accurate reference data are not readily available. A shaded relief image of a subsection of a 25,000 ft. pass is shown in Fig. 2.

\section{CONCLUSION}

The upgrade of the EMISAR system has provided the DCRS with a high resolution topographic mapping instrument. Initial test have shown that the system has the potential to generate height images with vertical accuracies of less than one meter. To obtain high quality data consistently an airborne interferometer needs to be very accurately calibrated with respect to all parameters involved in the process. This work is in progress. The automatic generation of height maps without ground reference points also requires a very accurate navigation and attitude measurement system, which is presently under procurement. Careful evaluation experiments are on-going, but are most difficult as reference maps or data with sufficient height accuracy are not readily available.

\section{REFERENCES}

[1] R.M. Goldstein, H.A. Zebker, and C. Werner, "Satellite radar interferometry: two-dimensional phase unwrapping," Radioscience, vol.23, pp.713--720, Jul.-Aug. 1988

[2] S.N. Madsen, "On absolute phase determination techniques in SAR interferometry", SPIE conference proceedings, Orlando, Florida, April 1995

[3] S.N. Madsen, H.A. Zebker, and J. Martin, "Topographic mapping using radar interferometry", IEEE trans. Geoscience and Remote Sensing, vol. 31, no. 1, pp. 246256, Jan. 1993.

[4] E. Rodriguez and J. Martin, "Theory and design of interferometric synthetic aperture radars", IEE proc.-F, vol. 139, no. 2, pp. 147-159, Apr. 1992.

[5] E. Rodriguez, D.A. Imel, and S.N. Madsen, "The accuracy of airborne interferometric SAR", IEEE trans. Aerospace and Electronic Syst., accepted for publication.

[6] S.N. Madsen, P.A Rosen, D.A. Imel, J. Martin, and S. Hensley "A third generation interferometric processor for interferometric processing", in preparation.

[7] David R. Stevens, Ian G. Cumming, and A. Lawrence Gray, "Options for Airborne Interferometric SAR Motion Compensation”, IEEE Trans. GRS, vol. 33, pp. 409-420, March 1995

[8] Sorren N. Madsen and Howard Zebker, "Imaging Radar Interferometry", chapter 17 in Manual of Remote Sensing, Vol. III, 1996, in press. 